\title{
EL CRIMEN ORGANIZADO TRANSNACIONAL: MECANISMOS DE LUCHA PREVISTOS EN LA ESTRATEGIA DE SEGURIDAD NACIONAL 2013
}

\author{
Raquel Barras ${ }^{1}$ \\ UNISCI
}

\begin{abstract}
Resumen:
El crimen organizado es un problema de primer orden que se ha mundializado usando los canales propios de la Globalización. La proliferación de este tipo de actividades delictivas constituye una de las principales amenazas para la seguridad. La Estrategia de Seguridad Nacional ha incluido el crimen organizado en sus líneas de acción, puesto que es uno de los retos más complejos. Amenazas globales requieren respuestas globales y este artículo pretende mostrar una serie de claves que se llevan a cabo en países de nuestro entorno para hacer frente a esta amenaza, donde destaca la cooperación y el enfoque trasversal y multidisciplinar.
\end{abstract}

Palabras clave: crimen organizado transnacional, seguridad, Estrategia Seguridad Nacional, amenazas globales, poder.

Title in English:"Transnational Crime: Mechanism to Fight it as Foreseen in the National Security Strategy 2013"

\section{Abstract:}

Abstract: Organized crime is a major global threat that has grown around the world. This threat uses the channels of Globalization. The proliferation of this kind of criminal activity is one of the main threats to global security. The Spanish National Security Strategy has included organized crime in their main lines of action. Global threats require global responses. This article tries to show the different key instruments held in our neighbouring countries to deal with this threat. In this sense, one of the most important tools is ooperation among nations in order to implement a multidisciplinary approach.

Keywords: Transnational Organized Crime, Security, Spanish National Security Strategy, Global Threat, Power.

Copyright (C) UNISCI, 2014.

Las opiniones expresadas en estos artículos son propias de sus autores, y no reflejan necesariamente la opinión de UNISCI. The views expressed in these articles are those of the authors, and do not necessarily reflect the views of UNISCI.

\footnotetext{
${ }^{1}$ Raquel Barras Tejudo es investigadora junior de UNISCI y miembro del Foro Hispano-Argelino. E-mail: raqueltejudo@yahoo.es. 


\section{Introducción}

El proceso de globalización ha supuesto una superabundancia de oportunidades en diversos ámbitos político, económico, social y cultural ${ }^{2}$, permitiendo el desarrollo de las naciones, un mayor grado de libertad e intercambio de mercancías, servicios y personas. Esto, junto con los avances científicos y tecnológicos, la masificación de los medios de comunicación y transportes, etc. ha permitido crear un mundo interconectado en tiempo real ${ }^{3}$. En definitiva, la sociedad global, la superación de las fronteras y la interdependencia entre los países, han dinamitado los anteriores paradigmas de seguridad, creando un nuevo escenario estratégico global irreversible ${ }^{4}$.

Este contexto internacional de posibilidades y prosperidad, lleva aparejado, de forma intrínseca, una serie de nuevos riesgos y amenazas. Así, la criminalidad organizada se ha ido extendiendo y ampliando paralelamente al proceso de globalización, encontrando multitud de canales y oportunidades, y convirtiéndose, de un tiempo a esta parte, en una de las líneas prioritarias de acción en el ámbito de la seguridad internacional por parte de los Estados.

Se calcula que el crimen organizado genera al año en torno a 870.000 millones de dólares, una cantidad que equivaldría al 1,5\% del PIB mundial ${ }^{5}$. La amenaza que representan las redes criminales afecta a todos los países y regiones del mundo. No obstante, el origen del crimen se produce de forma exponencial en lugares con débiles instituciones públicas o bien en lugares donde parte del territorio no se encuentra bajo el control de las autoridades competentes. De forma gráfica, 'crimen organizado transnacional' es que "el $90 \%$ de la heroína europea proceda de adormideras cultivadas en Afganistán, y se distribuya a través de las redes de delincuentes de los Balcanes, que son responsables, a su vez, de cerca de 200.000 del total de las mujeres víctimas del comercio sexual en todo el mundo; o que el éxtasis, fabricado primordialmente en Holanda, sea enviado a Estados Unidos por grupos del crimen organizado israelíes"

\footnotetext{
${ }^{2}$ Ulrich, Beck (2000): What is Globalization?, Cambridge Polity Press.

${ }^{3}$ Globalización entendida como "intensification of global interconnectedness: political, economic, military and cultural", ver en Kaldor, M. (1999): New \& Old Wars: Organized Violence in a Global Era, Stanford, p. 3.

${ }^{4}$ Feal Vázquez, Javier: “Amenazas transnacionales", Ministerio de Defensa, CESEDEN, Boletín de información del CESEDEN, n 295 (Julio 2006).

${ }^{5}$ Datos facilitados en 2012 por la Oficina de Naciones Unidas contra la Droga y el Delito (UNODC).

${ }^{6}$ Dobriansky, P.: “El crecimiento explosivo del Crimen Organizado Transnacional", Subsecretaria de EEUU para Asuntos Mundiales. Departamento de Estado de EEUU (Agosto de 2001).
} 


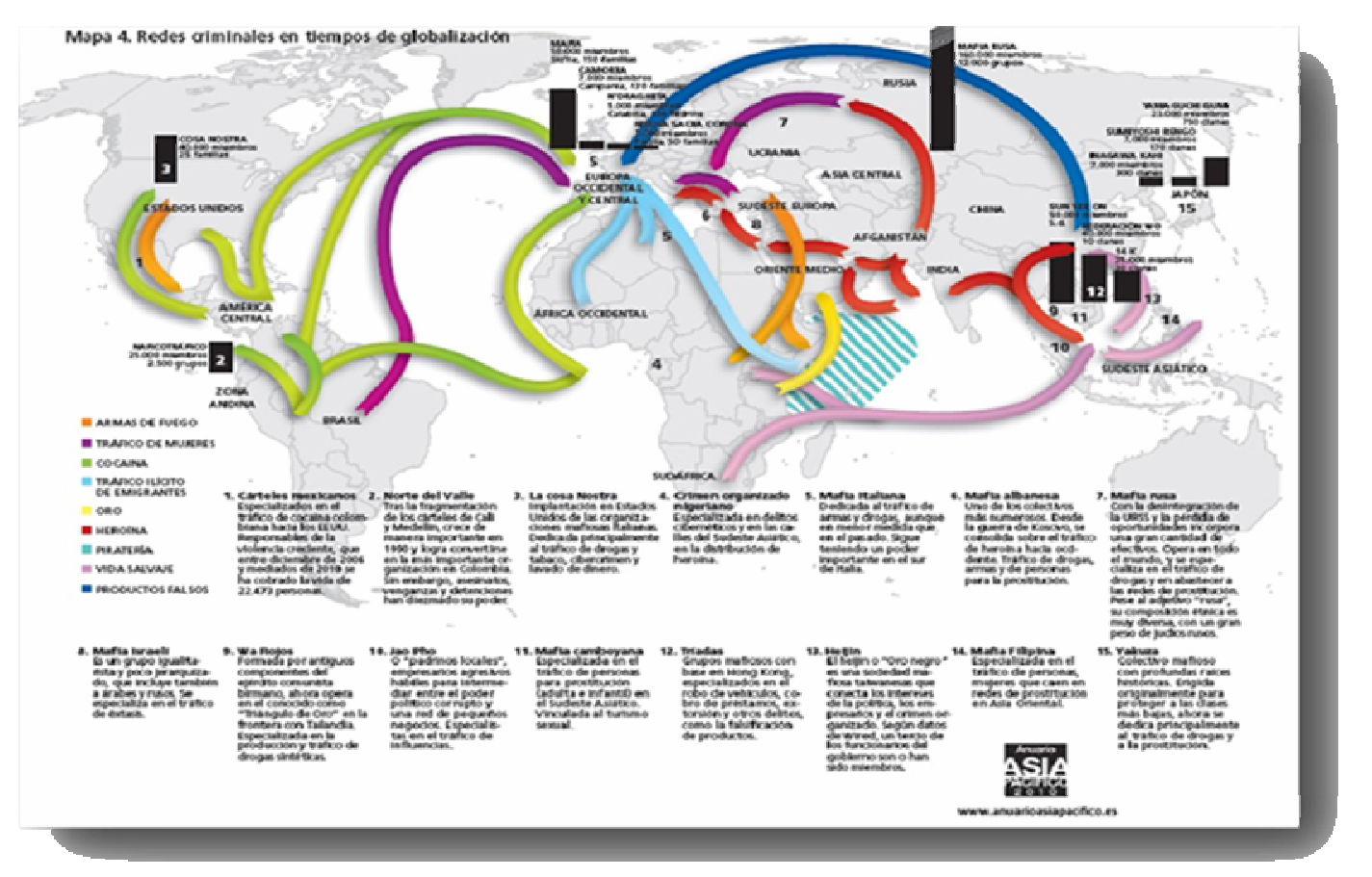

Fuente: Anuario Asia Pacífico

Este artículo analiza cómo la nueva Estrategia de Seguridad Nacional (ESN) presentada en el año $2013^{7}$, aborda el problema del crimen organizado transnacional. El artículo se divide en cinco partes: en primer lugar se plantea, a modo de introducción, la mundialización del crimen y su injerencia en los asuntos de seguridad en los últimos años, al tiempo que realiza una contextualización internacional de los mecanismos de lucha en tres niveles: internacional, europeo y nacional. Posteriormente el artículo presenta una foto fija del crimen en nuestro país y sus conexiones transnacionales (datos, localización y perfil delincuencial). Del mismo modo, se realiza un planteamiento y análisis general del tratamiento que el crimen organizado transnacional recibe en la nueva Estrategia de Seguridad Nacional: por un lado se realiza una comparación entre la ESN 2013 y la EES 2011 ${ }^{8}$; a continuación se lleva a cabo un examen de los problemas, carencias y puntos débiles que presenta la ESN para hacer frente a esta nueva amenaza, al tiempo que se realiza un análisis en clave comparada con otras ESN de países de nuestro entorno 9 . Por último, y a modo de conclusión, se realiza una re-visión sobre el contenido planteado en la vigente ESN para luchar contra el crimen organizado, que permita identificar los puntos que deben ser mejorados y que pueden ser de algún modo 'importados' de las experiencias en la lucha contra el crimen organizado de los países que, como nosotros, sufren esta lacra en su seguridad nacional.

\footnotetext{
7 "Estrategia de Seguridad Nacional" (2013).

8 "Estrategia Española de Seguridad" (2011).

${ }^{9}$ En particular: Francia, Italia, Reino Unido, Finlandia, Noruega, Estados Unidos, Australia y Japón.
} 


\section{Contexto internacional: Mecanismos de lucha ${ }^{10}$}

El narcotráfico, el tráfico de seres humanos, las redes de prostitución, el terrorismo ${ }^{11}$, el tráfico de armas, la corrupción, el lavado de dinero, la comercialización de medicamentos fraudulentos, las extorsiones, la piratería, el tráfico de residuos tóxicos, recursos naturales robados o animales protegidos, son las principales actividades a las que se dedican los conglomerados de delincuencia organizada. La economía globalizada favorece el anonimato y la extraterritorialidad en lo que al crimen organizado se refiere. Asimismo, fenómenos como los conflictos armados y la proliferación de armamentos, suponen importantes caldos de cultivo para la fermentación de actividades delictivas. El crimen organizado se ha convertido en uno de los principales problemas de las sociedades actuales, por lo que, organizaciones tanto de carácter internacional como regional han identificado esta amenaza y han creado una serie de mecanismos para combatirla.

\subsection{A nivel internacional}

Para Naciones Unidas la noción de crimen organizado es muy compleja por todas las derivaciones que comporta, si bien la Organización define organización criminal como: " $a$ structured group of three or more persons, existing for a period of time and acting in concert with the aim of committing one or more serious crimes or offences [...], in order to obtain, directly or indirectly, a financial or other material benefit ${ }^{\prime 12}$.

A partir del año 1994, desde la celebración en la ciudad de Nápoles de la Conferencia Mundial sobre Delincuencia Organizada Transnacional bajo los auspicios de la ONU, se desarrolló una nueva corriente de concienciación sobre esta materia, vertebrando un entorno legal propicio para luchar contra la delincuencia. A este respecto, destacan por un lado los mecanismos que pone en marcha la Convención de las Naciones Unidas contra el Crimen Organizado Transnacional y los tres protocolos adicionales (2000). Las primeras directrices abordadas en la Convención de Palermo, constituyen el marco de acción para el Programa Global contra el crimen organizado de la Oficina de Naciones Unidas contra la Droga y el Delito (UNODC); incluyendo cinco programas adicionales, centrados en ámbitos específicos: trata de personas, lavado de activos, corrupción, terrorismo y asistencia legal. Del mismo modo, puede subrayarse que la OTAN, ya introdujo en el año 1999, en su revisión del Concepto Estratégico, la delincuencia organizada como uno de los retos para la seguridad en los Estados miembros. Asimismo, en el año 2004, en el Informe presentado por las Naciones Unidas 'A more secure World: Our shared responsibility' ${ }^{13}$, se señalaba a la delincuencia organizada transnacional como una de las seis mayores amenazas a la estabilidad mundial. Actualmente el crimen organizado se ha incrementado exponencialmente y se ha convertido en un problema de primer orden para la seguridad de todos los países.

\footnotetext{
${ }^{10}$ Ver: Barras, R.: "España y el crimen organizado: ¿Asignatura pendiente de la Estrategia Española de Seguridad?", IUGM, V Jornadas de Estudios de Seguridad (Mayo de 2013), en http://iugm.es/uploads/tx_iugm/ACTAS_V_JORNADAS_DE_EST_DE_SEG.pdf.

${ }^{11} \mathrm{SC} / \mathrm{Res} / 1373$ de 28 de septiembre de 2001, sobre las amenazas a la paz y seguridad internacionales por actos de terrorismo, en http://www.un.org/es/común/docs/?symbol=S/RES/1373\%282001\%29.

${ }^{12}$ UN Convention against Transnational Organized Crime. Art. 2. AG/55/25 (2001).

${ }^{13}$ Informe elaborado por el Grupo de alto nivel sobre las amenazas, los desafíos y el cambio de la ONU: "A more secure World: Our shared responsibility", en

https://www.un.org/en/peacebuilding/pdf/historical/hlp_more_secure_world.pdf.
} 
En este sentido, a nivel internacional se han puesto en marcha diversos $\operatorname{Tratados}^{14}$ que versan sobre temas específicos, además de la citada Convención contra la Delincuencia Organizada Transnacional: la Convención contra la Corrupción ${ }^{15}$, Convención Única sobre estupefacientes ${ }^{16}$, Convenio sobre Sustancias Psicotrópicas ${ }^{17}$, Convención contra el Tráfico Ilícito de Estupefacientes y Sustancias Psicotrópicas ${ }^{18}$ así como otros Convenios antiterroristas. Adicionalmente se han puesto en marcha numerosas campañas ${ }^{19}$, $\operatorname{comisiones}^{20}$, congresos $^{21}$ e informes ${ }^{22}$, que ofrecen amplia información sobre la situación, tendencias y análisis actualizado de los mercados del crimen. Del mismo modo, cabe destacar las diversas herramientas legales ${ }^{23}$ que se han puesto en marcha en el seno de la organización.

La lucha contra el crimen organizado trasnacional, cuenta con un amplio abanico de herramientas que proveen de información sobre los distintos negocios del crimen. En cuanto a la situación de las drogas ilícitas, se realizan análisis detallados sobre las tendencias en la producción, el tráfico y el consumo en diferentes mercados (opio/heroína, coca/cocaína, cannabis y estimulantes de tipo anfetamínico). En cuanto a la trata de seres humanos, un fenómeno que afecta a todos los países (se han constatado víctimas de trata 127 países), cabe destacar que, a pesar de que muchos países han aprobado recientemente leyes sobre esta materia, aún es insuficiente la detección del problema, así como una lucha verdaderamente articulada a nivel global al respecto. Otro aspecto incipiente, y que debe ser más desarrollado en el futuro es la justicia penal y las políticas de prevención de los delitos realizados por los sindicatos del crimen.

\footnotetext{
14 Estos acuerdos, proporcionan el fundamento jurídico de la acción contra la delincuencia organizada transnacional, y reflejan el acuerdo de la comunidad internacional sobre la tesis de que para abordar este problema de forma eficaz, es esencial la colaboración de todos los estados afectados o involucrados.

${ }^{15}$ Resolución 55/61 de diciembre de 2000, de la Asamblea General. Reconoció la necesidad de crear un instrumento jurídico internacional eficaz contra la corrupción, independiente de Convención de las Naciones Unidas contra la Delincuencia Organizada Transnacional (resolución 55 /25, anexo I). En este sentido, el Convenio (aprobado por el Comité Ad Hoc) fue adoptada por la Asamblea General en su resolución 58/4 de 31 de octubre de 2003. La Asamblea General, en su resolución 57/169, de 18 de diciembre de 2002, aceptó el ofrecimiento del Gobierno de México para ser sede de una conferencia política de alto nivel en Mérida para la firma de este documento. Así, la Convención de las Naciones Unidas contra la Corrupción Entró en vigor el 14 de diciembre de 2005. Actualmente hay 140 Estados signatarios y 170 forman parte.

${ }_{16}^{16}$ Convención Única sobre Estupefacientes de 1961. Enmendada por el Protocolo que modifica la Convención Única sobre Estupefacientes de 1961. Nueva York, 8 de agosto 1975.

${ }^{17}$ Convenio Sobre Sustancias psicotrópicas. Viena, 21 de febrero 1971.

${ }^{18}$ Convención contra el Tráfico Ilícito de Estupefacientes y Psicotrópicas Naciones Unidas Sustancias, 1988. Esta Convención establece medidas integrales contra el tráfico de drogas, lavado de dinero y contra Disposiciones (incluyendo el desvío de precursores químicos). Se prevé la cooperación internacional a través de, por ejemplo, la extradición de narcotraficantes, la entrega vigilada y remisión de las actuaciones.

${ }_{19}^{19}$ Día Mundial de las Drogas, el 26 de junio; Día contra la Corrupción el 9 de diciembre de cada año.

${ }^{20}$ Se crean las siguientes Comisiones: de Estupefacientes; de Prevención del Delito y Justicia Penal; de Gobernanza y Finanzas y la Secretaría a los Órganos de Gobierno. Asimismo el Consejo Económico y Social creó una mesa redonda dedicada a la importancia de la fiscalización de drogas, prevención del delito y justicia penal en el contexto de la agenda de desarrollo post- 2015.

${ }^{21}$ El próximo congreso sobre la materia está previsto que se celebre en Qatar en el año 2015. Anteriormente, y con una periodicidad de 5 años se han venido celebrando Congresos sobre esta materia, desde que se iniciara en el año 1955, en Ginebra.

${ }^{22}$ Informes de carácter anual: Informe Mundial sobre las Drogas, Informe mundial sobre la trata de personas; evaluaciones de la amenaza del crimen organizado transnacional; estadísticas; estudios y publicaciones; boletín de Estupefacientes contiene artículos técnicos y científicos sobre temas relacionados con los estupefacientes; Foro sobre el Delito y la Sociedad; Encuestas; y diversas encuestas sobre: Monitoreo de Cultivos Ilícitos y tendencia de la delincuencia (CTS), entre otras.

${ }^{23}$ Herramientas como la Biblioteca Legal; bases de datos sobre tráfico de seres humanos; directorios de autoridades nacionales competentes; Asistencia Legal Mutua; redes de Cooperación Internacional.
} 
Cabe destacar, debido a la percepción creciente de la ciudadanía sobre la corrupción a nivel institucional ${ }^{24}$, la existencia de mecanismos expresamente diseñados de lucha contra la corrupción, como la Anti-Bribery Convention de la $\mathrm{OCDE}^{25}$. Se trata de una convención de la OCDE destinada a la reducción de corrupción en los países en desarrollo mediante el fomento de las sanciones contra el soborno en las transacciones comerciales internacionales llevadas a cabo por empresas con sede en los países miembros de la Convención. Su objetivo es crear una auténtica igualdad en el entorno de los negocios internacionales.

\subsection{A nivel Europeo}

El crimen organizado en el continente europeo está evolucionando con rapidez, principalmente como consecuencia de la ampliación de la Unión Europea, la apertura de fronteras entre los Estados miembros, el aumento de intercambios entre los países de Europa Central y del Este y el incremento de comunidades extranjeras en los diferentes Estados ${ }^{26}$. La ausencia de antiguas fronteras ha producido un efecto pernicioso e indeseado: la eliminación de obstáculos para el crimen, y la aproximación y acercamiento del territorio europeo a países que presentan un alto grado de operatividad de grupos criminales. Así, la incursión de la potente mafia albano-kosovar, ha logrado aprovechar el caos imperante en los Balcanes debido a los Estados débiles, y, en algunos casos, los escenarios post-bélicos, tras la desarticulación de la Unión Soviética. Así, el Este de Europa se ha convertido en una verdadera puerta de acceso para el tráfico de drogas ${ }^{27}$, armas y seres humanos.

Pese a las medidas que se han ido adoptado por parte de las autoridades, cada vez más conscientes del incremento de la actividad delictiva, el crimen organizado sigue constituyendo una de las más graves amenazas para la seguridad de Europa. En este sentido, las actividades delictivas se han extendido a nuevas áreas geográficas, al tiempo que se ha incrementado el número de productos objeto del tráfico ilícito. A nivel europeo, se calcula que podría haber alrededor de 4.000 bandas organizadas, cuyos ámbitos de actuación van desde el narcotráfico hasta el contrabando de mercancías, pasando por el tráfico de seres humanos o los delitos financieros ${ }^{28}$.

En el ámbito europeo este problema ha sido identificado en numerosas ocasiones, por primera vez en 1998, con definiciones previas', o la 'Criminal Law Convention on Corruption $^{30}$ del Consejo de Europa y en vigor desde julio del año 2002, o, actualmente la puesta en marcha del Plan de acción contra el Crimen Organizado para el periodo 2014-

\footnotetext{
24 "Global Corruption Barometer 2013", Transparencia Internacional, en http://issuu.com/transparencyinternational/docs/2013 globalcorruptionbarometer_en/1?e=2496456/3903358.

${ }^{25}$ Convention on combating bribery of foreign public officials in international business transactions and related documents, en http://www.oecd.org/daf/anti-bribery/ConvCombatBribery_ENG.pdf.

${ }^{26}$ Palma Herrera, J.M: "El sistema estadístico de criminalidad y su eficacia en el estudio de la conexión entre criminalidad organizada e inmigración. España", Revista Electrónica de Ciencia Penal y Criminología, nº 14-r1 (2012), pp. 1-45, en http://criminet.ugr.es/recpc/14/recpc14-r1.pdf.

${ }^{27}$ El contrabando de estupefacientes a través del Adriático desde Albania y Montenegro ha alcanzado en nuestros días "proporciones increíbles", ver en: Declaraciones de Napolitano, G. mientras era Ministro de Interior de Italia, en una conferencia sobre narcóticos.

${ }^{28}$ De acuerdo con los datos de Europol: "SOCTA 2013. EU Serious and Organised Crime Threat Assessment", en https://www.europol.europa.eu/sites/default/files/publications/socta2013.pdf

${ }_{29}$ Véase la Acción común sobre la tipificación penal de la participación en una organización delictiva en los Estados miembros de la UE (DO L 333 de 9.12.1998); doc. 6204/2/97 ENFOPOL 35 REV.

30 "Criminal Law Convention on Corruption", Consejo de Europa, Estrasburgo (27 de enero de 1999), en http://conventions.coe.int/Treaty/EN/Treaties/Html/173.htm
} 
$2019^{31}$. Las organizaciones criminales internacionales que operan en el territorio de la UE; por ejemplo "las mafias no se circunscriben a un área geográfica determinada. En Alemania, las mayores organizaciones criminales internacionales que actúan son turcas o rusas. Es un reto europeo que necesita una solución europea" 32 .

Otro mecanismo a tener en cuenta es el Programa de Estocolmo 'Una Europa abierta y segura que sirva y proteja al ciudadano ${ }^{33}$, del año 2010 , y que será revisado en el presente año. Entre las medidas más destacadas de lucha contra el crimen se encuentran: evaluación de la labor realizada por la Red Europea de Prevención de la Delincuencia (REPD), Observatorio para la prevención de la delincuencia (OPD), apoyar a los Estados miembros y las instituciones de la Unión cuando adopten medidas preventivas y promoverlas, e intercambiar prácticas idóneas.

No obstante, en lo que respecta al escenario europeo, se ha generado numerosa legislación comunitaria así como la inclusión en la agenda de Justicia e Interior (JAI) de la Unión Europea del año 2004, o, por ejemplo el desarrollo de un concepto estratégico para hacer frente a la delincuencia organizada. Así, con el establecimiento de la Corte Penal Internacional en 1998 de forma permanente, mediante la aprobación del Estatuto de Roma, se alcanza por vez primera, un consenso para la creación de un mecanismo con presencia fiscal inmediata, que es capaz de dar respuesta a la brevedad del juzgamiento, así como la extradición y entrega de personas acusadas de haber cometido actos delictivos ${ }^{34}$. En este escenario es donde se enmarca la INTERPOL, ya que por su estructura, número de Estados implicados, red de comunicación y sistemas científicos disponibles, mecanismos como: la extradición, la entrega vigilada o el agente encubierto están destinados a ser la herramienta inmediata y previsiblemente exitosa contra el crimen organizado transnacional ${ }^{35}$. Cabe destacar el papel fundamental de la cooperación operativa, que se ha articulado a través de la Estrategia de Seguridad Interior Europea. En este sentido, el Comité de Seguridad Interior (COSI) trabaja estrechamente con agencias, instituciones y organismos como FRONTEX (recopilación e intercambio de fronteras exteriores), EUROPOL (coordinación operativa) y EUROJUST (coordinación de autoridades).

A pesar de la existencia de instrumentos internacionales para la lucha contra el la delincuencia organizada ${ }^{36}$ en el marco legal, es necesario establecer mecanismos de control real y efectivo enfatizando en la cooperación y la coordinación operativa, las actividades de análisis conjunto, la evaluación y el control, la transferencia de técnicas y métodos, la formación y el intercambio de expertos, así como las actividades de sensibilización y difusión,

\footnotetext{
${ }^{31}$ El presente año ha entrado en vigor el denominado Plan de acción para combatir el crimen organizado a nivel nacional, europeo e internacional. El Parlamento Europeo aprobó en pleno el pasado octubre una resolución no legislativa de puesta en marcha de dicho plan.

${ }^{32}$ De acuerdo con el Informe final de la Comisión Especial del Parlamento Europeo contra la Delincuencia Organizada, la Corrupción y el Blanqueo de Dinero, redactado por el Eurodiputado italiano Salvatore Iacolino (20 de septiembre de 2013).

${ }^{33}$ OJ C 115, 04/05/2010, en

http://eur-lex.europa.eu/legalcontent/ES/ALL/;jsessionid=hLhpTGLCHp7fC2TFHVyQqKv3BmBcpYlCDLvz14TxBDhVDQh2442d!167260 4281?uri=CELEX:52010XG0504(01).

${ }^{34}$ Barras, R y Herrero, R.: "Globalización y crimen organizado. Mecanismos de lucha contra el crimen: la Inteligencia”, Inteligencia y Seguridad: Revista de análisis y prospectiva, no 6 (Junio 2009).

${ }^{35}$ Montaño, E. (2005): Estrategias de cooperación para contrarrestar la violencia política del terrorismo y del crimen organizado, La Paz, Bolivia.

${ }^{36}$ Caselli, G.C. (2005): "Los instrumentos internacionales en la lucha contra el crimen organizado", en Camara de Landa, E. y Morabito, S. (coord.): Mafia, Ndrangheta, camorra: en los entresijos del poder paralelo, Valladolid, Secretariado de Publicaciones e Intercambio Editorial.
} 
que deben erigirse paulatinamente como prácticas fundamentales y de concurrencia entre los países $^{37}$. Finalmente hay que mencionar que la UE ha desarrollado varias Estrategias de Lucha contra las Drogas.

\subsection{A nivel nacional}

Al tiempo que las actividades delictivas han aumentado en los últimos años, y han alcanzado en nuestro país una mayor repercusión mediática, las Fuerzas y Cuerpos de Seguridad del Estado han respondido a este fenómeno, creando y potenciando diversas unidades operativas especializadas $^{38}$. En el seno del Cuerpo Nacional de Policía se ha creado GRECO (Grupos de Respuesta Especial para el Crimen Organizado) cuya labor principal es la captación de información y la lucha contra la delincuencia organizada en general, abarcando todas las actividades ilícitas de estos grupos criminales. Este órgano cuenta con presencia en las principales ciudades con destacada actividad del crimen organizado ${ }^{39}$.

En el ámbito de la Guardia Civil, se ha puesto en marcha el denominado Plan de Actuación Contra el Crimen Organizado (PACCO). Se trata de una restructuración y creación de nuevos equipos, con un objetivo determinado: la centralización de la información en todo lo referente a la delincuencia organizada ${ }^{40}$. La función principal de estos grupos es recabar y analizar toda la información derivada de sus intervenciones a la UCO, órgano que se encargará de centralizar y examinar todos los datos que se generen en las Unidades de la Guardia Civil relacionados con la delincuencia organizada.

Otro ámbito que recibe especial atención por parte de las Fuerzas y Cuerpos de Seguridad del Estado, es el de la lucha contra los delitos fiscales y financieros, donde destaca la creación de la Unidad Central de Delincuencia Económica y Fiscal, así como la Brigada de Blanqueo de Capitales (adscrita a la UDEF). Del mismo modo se ha puesto en marcha la Unidad de Agentes Encubiertos. Debido al incremento de la ciberdelincuencia, se ha procedido a crear las Brigadas de Investigación Tecnológica y los Equipos de Investigación Tecnológica (EDITE), así como los Grupos de Apoyo en Tecnología de la Información (GATI).

Cabe destacar el análisis del Plan estratégico para los próximos años o el Código Ético, así como la Policía 3.0 basada en los servicios electrónicos, el acercamiento de los ciudadanos a estos medios y la transparencia en el seno delos agentes del orden ${ }^{41}$. Como principal tarea se encuentra la coordinación en el seno de la propia policía, y la adaptación de todos los sistemas informáticos al Esquema Nacional de Seguridad; la consecución de una Administración sin

\footnotetext{
37 Calvani, S.: "La inteligencia es una herramienta eficaz en la lucha contra el crimen organizado", UN Interregional Crime and Justice Research Institute (UNICRI) (2006).

${ }^{38}$ Datos del Ministerio del Interior. Funciones descritas en la Web del Ministerio: “La dirección, impulso y coordinación de las actuaciones del Departamento en materia de crimen organizado, tráfico de drogas, blanqueo de capitales relacionado con dicho tráfico y delitos conexos", ver en: http://www.interior.gob.es/web/interior/el-ministerio/funciones-y-estructura/secretaria-de-estado-de-seguridad. ${ }^{39}$ En Galicia, con sede en Pontevedra, Canarias con su oficina en Las Palmas, Cádiz (con oficina en Chiclana), Costa del Sol, con oficinas en Marbella y Málaga, el Levante, con sedes en Benidorm y Orihuela, y Baleares, con oficina en Ibiza, además de las operativas en Barcelona y Madrid.

${ }^{40}$ Así, se han creado los llamados 'Equipos contra el Crimen Organizado' (ECO), dependientes funcionalmente de la Unidad Central Operativa (UCO), donde se abrieron oficinas en Alicante y en Málaga.

${ }^{41}$ Reunión en Madrid de 330 mandos de toda España para tratar problemas y soluciones del Cuerpo. A la reunión acudió también el Secretario de Estado de Seguridad, Francisco Martínez, y la jornada fue clausurada por el Ministro del Interior, Jorge Fernández Díaz; $A B C, 11$ de abril 2013, en http://www.abc.es/espana/20130411/abci-crimen-organizado-ciberdelincuencia-retos-201304102055.html
} 
papeles y ulteriormente llegar a interconectar diversas bases de datos policiales con otras externas $^{42}$.

\title{
3. Radiografía del crimen organizado en España
}

En los últimos años, y de forma cada vez más alarmante, la criminalidad está más y más presente en nuestra vida cotidiana. Este problema de primer orden se ha multiplicado y mundializado, dando lugar a auténticos entramados y redes especializadas en diferentes delitos a gran escala. Europa en general y nuestro país en particular, son actualmente un paraíso para destacados grupos criminales, principalmente por su estratégica situación geográfica. En este sentido, España está considerada por parte de los principales grupos delictivos a nivel internacional como "el país de las oportunidades". En España la mayoría de los grupos que se dedican a la delincuencia organizada desarrollan más de una actividad, siendo la principal y más numerosa el tráfico de drogas. No obstante en el año 2012, las principales actividades delictivas de los grupos criminales en nuestro país fueron: el tráfico de drogas (lo practica un $60 \%$ de los grupos), de los cuales un $27 \%$ se dedica al comercio ilegal de cocaína y un $18 \%$ al hachís, un $16 \%$ de estos grupos criminales están especializados en los robos con fuerza, y un $10 \%$ a las estafas.

\subsection{Datos: composición de los grupos delictivos}

En el año 2012 en nuestro país se detectaron un total de 482 grupos criminales, de los cuales 277 , esto es un $57,5 \%$, fueron totalmente desarticulados. No obstante, 172 grupos criminales han sido desarticulados parcialmente, esto es, algunos de sus miembros fueron detenidos y existen operaciones policiales abiertas.

\section{Grupos investigados 482}

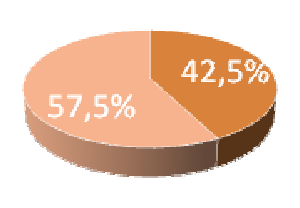

\author{
- Parcialmente \\ desarticulados \\ - Tolalmente \\ desarticulados
}

Fuente: elaboración propia a partir de datos del Ministerio del Interior

En la última década los grupos criminales han crecido exponencialmente en nuestro país. Así, en el año 2001, las bandas criminales no llegaban a 500 (486 bandas), mientras que en el año 2011, ya se superan los 650 grupos, en particular 662. No obstante se observa una tendencia creciente desde el año 2009 en el que se superó la barrera de los 600 bandas delictivas o grupos dedicados al crimen organizado en nuestro país, y que ha seguido incrementándose, con 616 en el año 2009, en el 2010, 622, y, en el 2011 alcanzando las 662 bandas detectadas. Llama la atención el descenso significativo entre el año 2011 y 2012, en cuanto al número de

\footnotetext{
${ }^{42}$ Como la de los Registros Civiles u otras del Ministerio de Justicia, o la transformación de las Salas del 091 en Centros Inteligentes de Mando, Comunicación y Control.
} 
bandas detectadas de 662 a 482, si bien, cabe destacar que en cuanto a su desarticulación, el porcentaje es similar $58 \%$ y $57,5 \%$ respectivamente.

\begin{tabular}{|l|l|l|}
\hline AÑO & $\begin{array}{l}\text { BANDAS } \\
\text { DETECTADAS }\end{array}$ & $\begin{array}{l}\text { BANDAS } \\
\text { DESARTICULADAS }\end{array}$ \\
\hline 2001 & 486 & $284(58 \%)$ \\
\hline 2002 & 594 & $384(64 \%)$ \\
\hline 2003 & 542 & $352(65 \%)$ \\
\hline 2004 & 494 & $326(66 \%)$ \\
\hline 2005 & 471 & $306(65 \%))$ \\
\hline 2006 & 482 & $310(64 \%)$ \\
\hline 2007 & 564 & $323(57 \%)$ \\
\hline 2008 & 538 & $273(51 \%)$ \\
\hline 2009 & 616 & $354(57 \%)$ \\
\hline 2010 & 622 & $306(49 \%)$ \\
\hline 2011 & 662 & $383(58 \%)$ \\
\hline 2012 & 482 & $277(57,5 \%)$ \\
\hline & & \\
\hline
\end{tabular}

Fuente: Ministerio del Interior

Del mismo modo, respecto a los datos de los primeros cinco meses del año 2013, en comparación con el año 2012, se ha incrementado en un $23 \%$ el número de investigaciones policiales, de las cuales, un $51 \%$ están relacionadas con el tráfico de drogas. De acuerdo con estos datos, la intensa actividad detectada en las últimas décadas, no nos permite predecir una progresiva reducción de dichas conductas en el futuro, a pesar de los intensos esfuerzos generados para su reducción por parte de las instituciones ${ }^{43}$.

En cuanto a las cifras que se desprenden de las actividades delictivas en nuestro país son realmente significativas. Sólo en el año 2012, se llegaron a incautar bienes por valor de 1.120 millones de euros en diversas operaciones ${ }^{44}$. En este sentido, se requisaron 14.509 kilos de

\footnotetext{
43 Giménez-Salinas, A.: "La delincuencia organizada en Europa: extensión, factores facilitadores y rasgos principales en la lucha contra el crimen organizado en la Unión Europea", Ministerio de Defensa, CESEDEN, Cuadernos del CESEDEN, nº 46 (Abril 2012).

${ }^{44}$ Informe Centro Inteligencia Contra el Crimen Organizado (CICO) (2012).
} 
cocaína, 119.187 kilos de hachís, 224 kilos de heroína y 7.912 unidades de éxtasis. Asimismo, se incautaron 1.670 vehículos, 118 embarcaciones, dos aeronaves, 459 armas de fuego, 201 armas blancas, 615 ordenadores, 6.455 teléfonos móviles, 427 inmuebles, 44 millones de euros y 408.891 euros falsos.

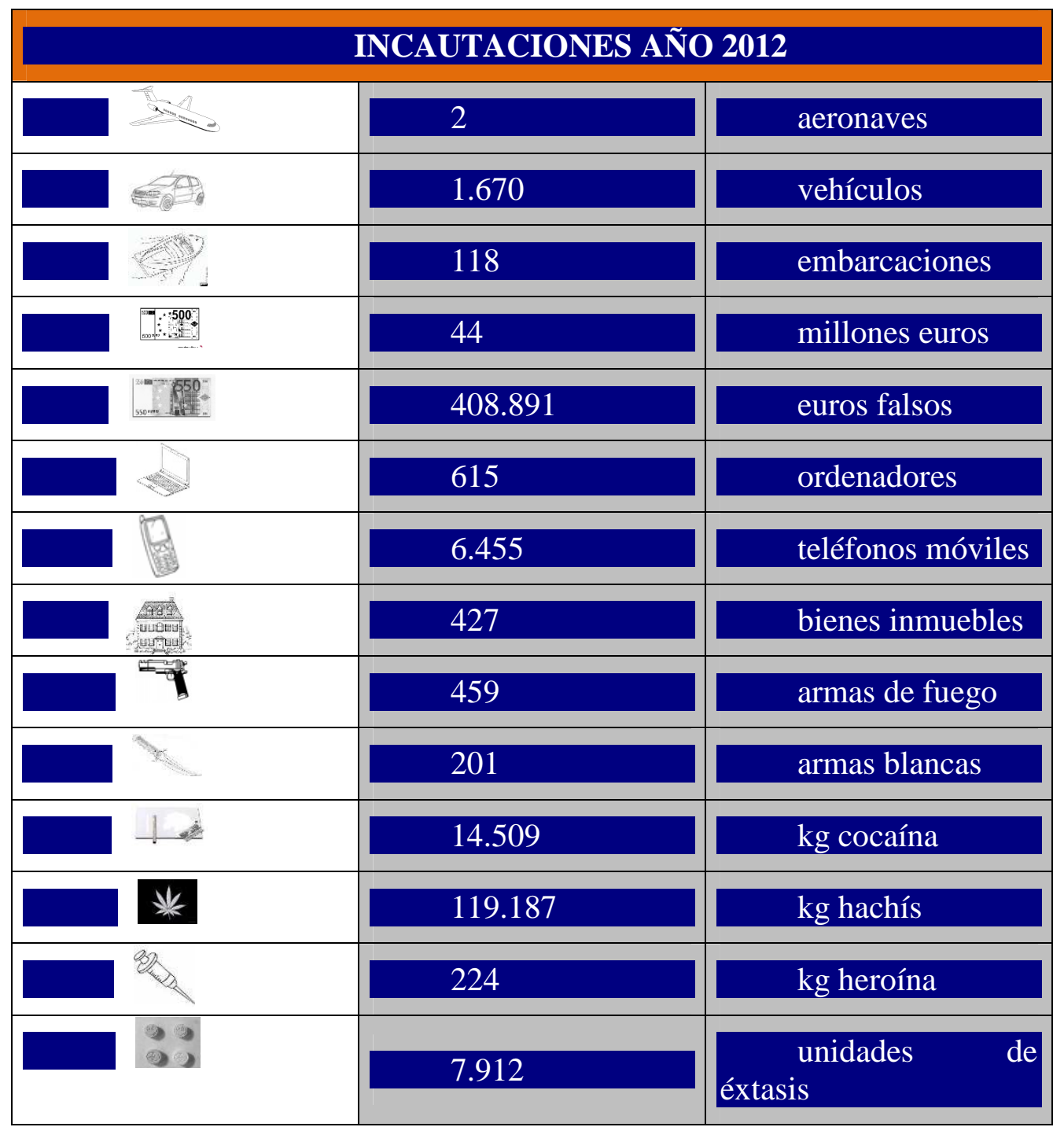

Fuente: Informe 2012 - Centro Inteligencia Contra el Crimen Organizado (CICO)

\subsection{Emplazamiento de los grupos criminales}

La extensión de la delincuencia organizada a todos los territorios y Estados, supone el verdadero reto para la seguridad. En este sentido, no hay ningún país que se encuentre eximido de sufrir este problema. No obstante, la península Ibérica ha registrado un dilatado número de actividades y recursos procedentes de los sindicatos del crimen, puesto que se ha convertido en la puerta de entrada a Europa, tanto para drogas procedentes de Sudamérica como del Magreb, esto es la cocaína y el hachís respectivamente. Adicionalmente nuestro país está denominado como uno de los 'puntos calientes' en cuanto a la inmigración ilegal se 
refiere, siendo la principal puerta de entrada de la mayoría de los inmigrantes ilegales del África Subsahariana ${ }^{45}$.

A la hora de situar y localizar las actividades delictivas en nuestro país, encontramos ciertas áreas con mayor presencia de grupos criminales. Aparte de Madrid, que como capital registra amplia presencia y actividad delictiva, el resto de zonas de concentración se corresponden principalmente con las zonas del litoral, y, en ocasiones, las archipelágicas. Por un lado el litoral levantino, es la franja costera con mayores focos de criminalidad. Adicionalmente, en la Costa del Sol provincias como Málaga y Cádiz registran alta actividad delictiva. En el caso del norte, Galicia ha sido históricamente una región ligada al tráfico de drogas.

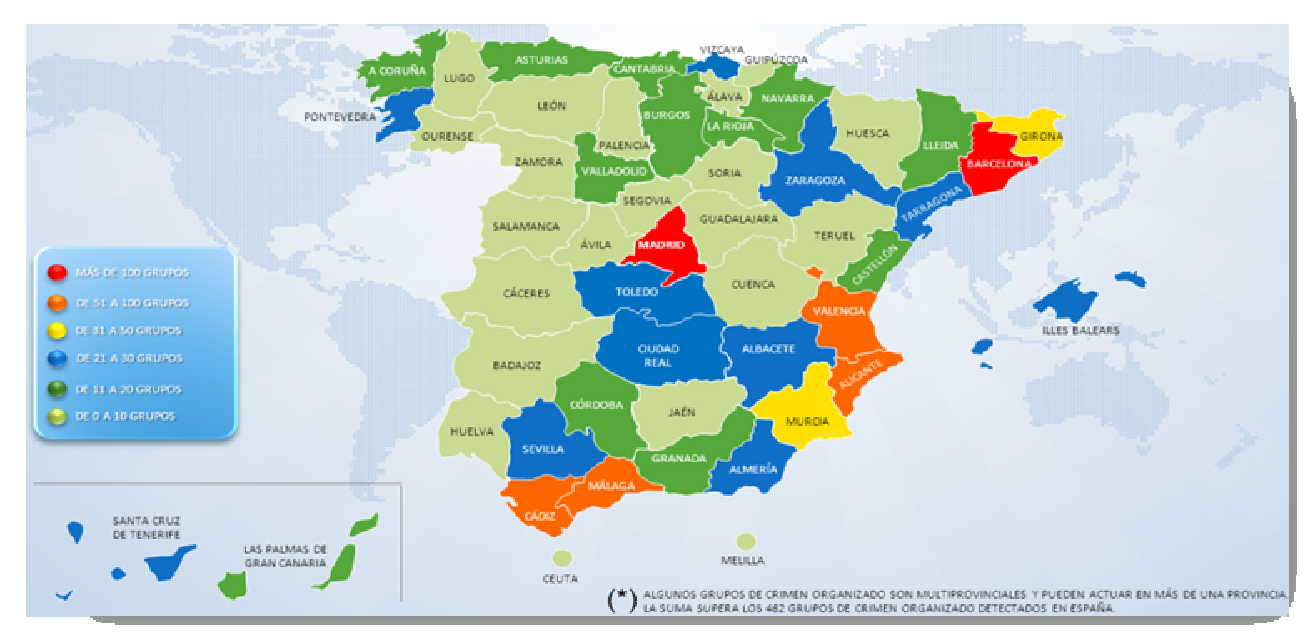

Fuente: Informe 2012, Centro Inteligencia Contra el Crimen Organizado (CICO)

\subsection{El perfil del crimen ${ }^{46}$}

A la hora de analizar los grupos criminales es necesario tener en cuenta una serie de variables como son su tamaño, nacionalidad y nivel de operatividad. En este sentido, durante el año 2012, un 79\% de los grupos de crimen organizado que actuaba en nuestro país llevaban creados y en activo menos de 3 años. Del mismo modo, el 69\% estaban conformados por personas de más de una nacionalidad y hasta un $67 \%$ de los mismos, llevaban a cabo su actividad delictiva a escala internacional.

\footnotetext{
${ }^{45}$ Giménez-Salinas, op. cit.

46 Ver Barras, R.: "España y el crimen organizado: ¿Asignatura pendiente de la Estrategia Española de Seguridad?", (IUGM) V Jornadas de Estudios de Seguridad (Mayo de 2013), en http://iugm.es/uploads/tx_iugm/ACTAS_V_JORNADAS_DE_EST_DE_SEG.pdf.
} 
Tamaño medio del grupo: 3 a 10 personas

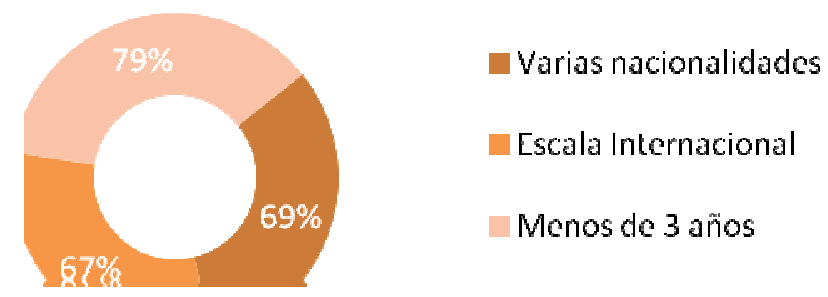

En cuanto a los conglomerados mafiosos que operan en nuestro país destacan: la mafia colombiana, la mafiya rusa, las triadas chinas, los grupos marroquíes, la mafia albanokosovar, y las redes nigerianas.

La mafia colombiana es uno de los grupos criminales más activos en nuestro territorio, centrada exclusivamente en el tráfico de cocaína. Cabe destacar que circunstancialmente realizan alianzas con determinados clanes (principalmente gitanos) para las labores de distribución y puntos de venta en el mercado de la droga. La propia actividad de tráfico de cocaína, lleva aparejado una serie de delitos, como por ejemplo los ajustes de cuentas y el mantenimiento de una red de sicarios pululando entorno a esos grupos. Así, han logrado que la cocaína sea el estupefaciente de mayor consumo en el viejo continente, a través de redes de distribución presentes en diversas ciudades.

Otro conglomerado criminal muy activo en nuestro país es la mafiya rusa ${ }^{47}$, que centran sus actividades en el tráfico de armas y drogas así como en el blanqueo de dinero. Los principales centros de operaciones están situados en Moscú y San Petersburgo, donde ejerce un flamante poderío económico. Particularmente, han encontrado refugio en Inglaterra, donde operan y controlan el mercado de la droga y la prostitución. Cabe destacar que también realizan extorsiones, amenazas y secuestros.

Las triadas o mafia china, son uno de los grupos criminales de mayor envergadura (más de 100.000 miembros) y de más largo alcance, con presencia en Europa, Estados Unidos, Japón, Australia y el Sudeste asiático. Entre sus principales actividades destaca el tráfico de seres humanos (también tráfico ilegal de trabajadores indocumentados) y de drogas, compitiendo con otros actores en el campo de la heroína. Adicionalmente, estos grupos mantienen una importante variedad de actividades delictivas: salas de fiestas, redes de prostitución; falsificación de documentos y bienes, contrabando, extorsión a empresarios chinos y ajustes de cuentas por encargo, etc. Desde sus bases en Guangdong, Hong Kong, y Taiwán, han establecido una compleja red, organizados en grupos denominados "tríadas", que son grupos reducidos e impenetrables; conectados jerárquicamente, aunque carentes de los lazos familiares propios de la mafia y altamente agresivos. En la mayoría de los casos estos grupos, están irremediablemente vinculados con el lavado de dinero en bancos y paraísos fiscales, para ocultar y blanquear los ingresos derivados de los actos ilícitos que llevan a $\mathrm{cabo}^{48}$.

Los grupos marroquíes son otros actores del crimen que operan en España. Especialmente centrados en el tráfico de hachís, tienen fuerte presencia en Andalucía, Madrid y la costa de Levante. Estos grupos se han convertido en auténticos referentes del tráfico de

\footnotetext{
${ }^{47}$ La mafia rusa es un conglomerado criminal de dimensiones planetarias, presente en al menos 26 países, que, con la caída del régimen comunista incrementa su poder.

${ }^{48}$ Barras, R y Herrero, R., op. cit.
} 
drogas en nuestro país, por lo que han conseguido aliarse con grupos criminales procedentes de Bélgica, Holanda y Reino Unido, logrando introducir importantes cantidades de cannabis en la península, si bien, en ocasiones introducen cocaína a través de España, Francia, Portugal e Italia ${ }^{49}$.

Como se han comentado anteriormente, en Europa, la caída de las antiguas fronteras ha permitido el asentamiento de un importante grupo criminal en nuestro país: la mafia albanokosovar. Estos grupos operan a nivel mundial y poseen conexiones trasnacionales. En España se han especializado en el robo con alto grado de violencia en viviendas, comercios y polígonos industriales. Del mismo modo, han conseguido consolidar redes tanto de prostitución como la realización de negocios con la mendicidad.

Por último, y principalmente relacionada con el tráfico de seres humanos, existe en nuestro país una red nigeriana, especializada en el negocio de la prostitución. De este modo, existe un tráfico de seres humanos abrumador de la región del África Subsahariana hacia España, considerada como la puerta de Europa. En particular, en estas redes se ven atrapadas mujeres subsaharianas obligadas a prostituirse puesto que están amenazadas con vudú y magia negra.

\subsection{Relación entre grupos criminales v grupos terroristas: narcoterrorismo}

De acuerdo con la ESN "los vínculos existentes entre las organizaciones criminales y los grupos terroristas son cada vez más estrechos". En este sentido, existe una clara relación entre grupos terroristas, actividades ilícitas y organizaciones criminales ${ }^{50}$, donde el principal nexo de unión radica en la búsqueda de fondos a través de actividades ilícitas como la droga, el blanqueo de dinero, el tráfico de armas, etc. A este respecto, "la amenaza para la paz y la seguridad regional no se debe, [...] a la presencia de un Estado especialmente fuerte y dominante en una región, sino todo lo contrario, a la debilidad e incluso inexistencia de una estructura estatal" ${ }^{\prime 51}$. No obstante, en los actuales escenarios de dificultad en diversos países, en términos políticos, económicos o sociales, se generan fructíferos caldos de cultivo para las mafias, donde ocasionalmente se establecen vínculos entre bandas criminales, grupos terroristas o grupos rebeldes.

El narcoterrorismo es entendido como una asociación estratégica entre mafias del narcotráfico y grupos de insurgencia armada, que comparten una serie de características, como su modo de operatividad o su clandestinidad. Sin embargo, la primera conclusión que se desprende de esta asociación es la necesidad de financiación de los grupos terroristas; el tráfico de drogas es una actividad lucrativa, que mueve cantidades ingentes de activos no comparables a otras formas de financiación. Se puede adivinar cierta metamorfosis degenerativa de grupos creados con un carácter marcadamente político, pero donde la capacidad de hacer "dinero fácil" se ha superpuesto a la consecución de objetivos políticos ${ }^{52}$.

\footnotetext{
${ }^{49}$ Varese, F.: "How Mafias migrate: the case of the "Ndrangheta in Northern Italy", Law \& Society Review, vol. 40, no 2 (Junio 2006).

50 "The close connection between international terrorism and transnational organized crime, illicit drugs, money-laundering, illegal arms-trafficking, and illegal movement of nuclear, chemical, biological and other potentially deadly materials”, en RES/CS/1373 (2001) (28 de septiembre de 2001).

51 Albares, J.M.: “Trabajar con socios difíciles: la promoción del desarrollo en los Estados frágiles", Real Instituto Elcano, ARI, $\mathrm{n}^{\mathrm{o}} 18$ (2005).

${ }^{52}$ Schmid, A. P.: Links between Terrorism and Drug Trafficking: A case of "Narco-terrorism?, International Summit on Democracy, Terrorism and Security, The Club of Madrid-Safe Democracy Foundation Madrid ( Marzo 2005).
} 
Las FARC en Colombia ${ }^{53}$ o los muyahidin en Afganistán ${ }^{54}$ son ejemplos de los estrechos vínculos entre grupos terroristas y crimen organizado, un gran desafío para la sociedad ${ }^{55}$. De este modo, el narcoterrorismo crea estructuras paralelas al Estado, la economía y los mercados, sustituyendo las tradicionales estructuras de poder, penetrando, en diverso grado en las instituciones asegurándose así cierto control y convirtiéndose en un auténtico problema de gobernabilidad.

\section{ESN y lucha contra el crimen organizado}

La lucha contra la delincuencia organizada fue incluida por primera vez en la Estrategia de Seguridad Nacional norteamericana del año 1994, en particular con la revisión de la misma, llevada a cabo por el Presidente estadounidense Bill Clinton. Así, se trataba esta actividad delictiva como un asunto de seguridad nacional, lo que supuso un replanteamiento de los conceptos de soberanía y transnacionalidad. De este modo, e imitando a Estados Unidos, numerosos gobiernos de otros países fueron incluyendo paulatinamente este fenómeno entre los principales riesgos o amenazas para la seguridad. Ejemplo de ello son el G-7 (grupo de países más industrializados del mundo) y el Consejo de Europa, donde se han realizado diversas cumbres sobre los problemas que causa la delincuencia organizada transnacional. Como ya se ha visto a lo largo del artículo, las diversas instituciones, tanto internacionales como europeas, han llevado a cabo numerosas y destacables acciones, que demuestran la creciente preocupación entorno a este tema. La proliferación de estrategias de seguridad nacionales ha puesto de manifiesto que, para afrontar los retos estratégicos del nuevo siglo, los países han vuelto a asumir un papel protagonista, revelándose de nuevo, como el principal actor estratégico ${ }^{56}$.

Como ya se ha definido a lo largo del artículo, la variación en los parámetros de seguridad y sobre todo en la naturaleza de las nuevas amenazas ha minimizado las capacidades propiamente militares, para, en su lugar, poner en marcha una serie de mecanismos centrados primordialmente en la cooperación, para hacer frente a unas amenazas cada vez más globales.

\footnotetext{
${ }^{53}$ En el caso colombiano, destacan las FARC, que obtienen más del 78\% (más de 1.000 millones de USD) de su presupuesto del narcotráfico, si bien no es el único caso en el país. En Colombia, se ha producido una simbiosis entre el antaño grupo terrorista, y la actual organización narcotraficante, lo que ha dado como resultado un narcoterrorismo afincado en la guerrilla.

${ }^{54}$ Asia central es una zona asolada por el tráfico de heroína, en la que la que países como Tayikistán y Kirguizistán se han convertido en importantes productores de opio, además de crear rutas de contrabando. Los muyahidin y los Talibán reproducen el esquema del narcoterrorismo colombiano, a través del contrabando y comercialización del opio. Estos señores de la guerra financiaban sus campañas militares obteniendo cuantiosos beneficios. Posteriormente con el control de los Talibán (90\% del territorio) el mercado de la adormidera pasó a sus manos siendo explotado en dos ámbitos: por un lado, en el restablecimiento de la paz y la seguridad en el campo (muy beneficioso para los agricultores); por otro, el contrabando es la base de la economía afgana, devastada por la guerra y las sanciones. Rashid, A: "La riqueza de la heroína. Las drogas y la economía Taliban", Web Islam, agosto de 2001, en http://www.webislam.com/articulos/25649-la_riqueza_de_la_heroina_las_drogas_y_la_economia taliban.html. 55 "Desarrollo de un concepto estratégico para hacer frente a la delincuencia organizada", COM (2005) 232 final, Bruselas, 2.6.2005 \{SEC (2005) 724\}.

56 Grupo de Estudios Estratégicos (GEES): "¿Dónde está la Estrategia Española de Seguridad?", Libertad Digital, 15 de febrero del 2011, en http://www.libertaddigital.com/opinion/gees/donde-esta-la-estrategiaespanola-de-seguridad-58434/.
} 


\subsection{Estrategia Española de Seguridad: 2011 versus 2013}

La Estrategia de Seguridad Nacional incluye bajo el epígrafe "los riesgos y las amenazas para para la seguridad nacional" el fenómeno del crimen organizado. En este sentido el "crimen organizado genera y activa otros riesgos y amenazas -fundamentalmente, el blanqueo de capitales-, que contribuyen a debilitar al Estado, obstaculizar el crecimiento económico y minar la democracia"57. Así, el citado documento prevé que la delincuencia organizada "aumentará en volumen, alcance y beneficios, principalmente a través de la explotación de nuevos mercados en regiones de crecimiento económico acelerado" ${ }^{\text {" }}$.

La Estrategia de Seguridad Nacional plantea un objetivo primordial: "impedir el asentamiento de los grupos criminales organizados, poner a disposición de la justicia a los que ya operan dentro de nuestras fronteras e impedir la consolidación de sus formas de actuación delincuencial" ${ }^{, 59}$. Asimismo, en la estrategia del año 2011, se centraban los esfuerzos en una triple dirección: mayores recursos al CICO, mejora de la coordinación entre organismos nacionales e internacionales y la mejora de forma permanente de los instrumentos jurídicos necesarios para poder luchar con eficacia contra todas las modalidades de crimen organizado. En el caso de la ESN del año 2013, se definen seis líneas estratégicas, que deben estar fundamentadas "en la colaboración y cooperación internacional, tanto en el ámbito público (policial, judicial y de inteligencia) como en el privado" ${ }^{, 60}$.

Las líneas de acción estratégicas propuestas en el documento de 2013 son, en primer lugar, la sensibilización y concienciación de la sociedad de que la lucha contra este fenómeno es global, trasciende nuestras fronteras y puede precisar el despliegue de efectivos en terceros países. En particular se debe generar un ambiente hostil al crimen, dificultando la implantación de estas organizaciones en nuestro país. En segundo lugar, la potenciación y mejora de los recursos, mecanismos y procedimientos de investigación policial relacionados con el tráfico de influencias en las instituciones y la corrupción en todas sus formas. En tercer lugar, la mejora de la eficacia policial mediante reformas normativas que fomenten y desarrollen la dirección centralizada y la coordinación en la lucha contra el crimen organizado, así como a través del refuerzo de la colaboración con los órganos judiciales y de la Fiscalía. A continuación, la mejora de la colaboración entre los centros y agencias de inteligencia estratégica, especialmente a través del fomento del intercambio de información. En quinto lugar, la potenciación de las investigaciones por blanqueo de capitales con la finalidad de minimizar su impacto en el ámbito económico y financiero. Por último, el tratamiento integral del problema del crimen organizado por medio de la implicación en la lucha contra este fenómeno de los actores nacionales públicos y privados, y especialmente, del mundo universitario.

Por el contrario su predecesora, la Estrategia Española de Seguridad, publicada en el año 2011, plantea la articulación por parte de los Estados de un enfoque integral de sus políticas ministeriales, así como la puesta en marcha de mecanismos para hacer frente a retos globales. Un aspecto importante es, que la percepción pública de esta amenaza está muy subestimada, quizá porque de alguna manera, se circunscribe únicamente al ámbito delincuencial, sin tener en cuenta las importantes interconexiones y cómo pude llegar a corromper las vigentes instituciones. A este respecto, cabe destacar como una carencia importante, que si bien las acciones contenidas tanto a nivel mundial como nacional tendrán

\footnotetext{
57 "Estrategia de Seguridad Nacional" (2013), p. 28.

${ }^{58}$ Ibid.

${ }^{59}$ Ibid., p. 39.

${ }^{60}$ Ibid., p. 43.
} 
una repercusión positiva pero no definitiva en la lucha contra el crimen, puesto que la delincuencia evoluciona velozmente a través de los nuevos avances y tecnologías, de la corrupción endémica de muchos gobernantes. A este respecto la delincuencia siempre va un paso por delante ${ }^{61}$.

Cabe destacar que la EES de 2011, detallaba de forma explícita los sistemas de información e inteligencia presentes a la hora de combatir el crimen organizado. En particular, pone en valor la puesta en marcha del CICO (Centro de Inteligencia contra el Crimen Organizado), con funciones de inteligencia criminal y coordinación operativa, que integra el Cuerpo Nacional de Policía y la Guardia Civil, y en el que participan también los Cuerpos de Policía Autonómica y el servicio de Vigilancia Aduanera, integrando también la colaboración de las Fuerzas Armadas en el supuesto de que fuese necesario. En definitiva, se trata de implementar más y mejor inteligencia entre los actores ya existentes. De alguna manera esta estrategia sí identifica los recursos humanos y materiales existentes.

\subsection{Carencias v puntos débiles de la ESN}

La ESN recoge en sus principales líneas de acción estratégicas seis puntos en los que debe centrarse la lucha contra el crimen organizado trasnacional. En este sentido, en un intento de reorientar y optimizar los recursos existentes, la estrategia plantea una serie de ideas que deberían ser detalladas y estructuradas respecto a las organizaciones y unidades presentes. En este sentido, la ESN 2013, debería perseguir como uno de los pilares y cimientos de la lucha contra el crimen la cooperación entre todos los organismos existentes, que se han explicitado en el apartado dos del presente artículo (mecanismos de lucha).

A la hora de identificar la amenaza la ESN 2013 realiza un análisis certero, tal y como pone de manifiesto el objetivo explicitado en la misma: "impedir el asentamiento de los grupos criminales organizados". No obstante, se debería profundizar y garantizar de alguna manera en sus líneas de acción, la necesaria imbricación en el seno de los organismos encargados de luchar contra la delincuencia transnacional. A este respecto, y tal y como se viene señalando en la mayoría de las estrategias de seguridad, la inteligencia es uno de los elementos básicos para garantizar la seguridad, ya que permiten elaborar una base informativa amplia y consolidada, ofreciendo información valiosa sobre los grupos criminales: organización y jerarquía, estructura financiera, métodos y prácticas delictivas, contactos y colaboraciones a nivel internacional y grado de operatividad e incidencia en los estados ${ }^{62}$.

Cabe destacar el coste elevado de la puesta en marcha de nuevas unidades, tanto en lo que se refiere a medios humanos (creación de puestos, selección, formación, etc.) como a lo que respecta a los medios materiales. Por lo que en la actual coyuntura económica supone un objetivo difícilmente alcanzable principalmente por motivos económicos y presupuestarios ${ }^{63}$.

Un aspecto ausente en la presente estrategia, es el necesario perfeccionamiento legislativo, que debería ser una herramienta más en la lucha contra la delincuencia organizada. En este sentido, no debería permitirse en modo alguno, que se produzcan errores estrictamente procesales o la existencia de determinadas lagunas legislativas, que se traducen en la excarcelación de capos mafiosos.

\footnotetext{
${ }^{61}$ Por ejemplo el fraude a través de Internet antes no existía.

${ }^{62}$ Calvani, op. cit.

63 Blanco, J. M.: "Estrategia Española contra el Crimen Organizado 2011-2014", Revista Atenea, 21 de noviembre del 2011, en http://www.onemagazine.es/noticia/6096/Sin-Especificar/Estrategia-Espanola-contra-elCrimen-Organizado-2011-2014.html.
} 
Otro aspecto relevante se produce en el ámbito de la prevención, en particular, la estrategia contempla la implicación, colaboración y participación tanto del sector público como del sector privado afectado. De este modo, para poder atacar el problema de raíz es necesario involucrar a los actores que ocasionalmente se asocian y facilitan la permanencia de ciertas actividades delictivas, incluyéndolas como parte de la solución.

\subsection{ESN en clave comparada: ¿qué se puede 'importar'?}

Los riesgos y amenazas a la seguridad han variado en los últimos tiempos, tal y como demuestran la mayor parte de los documentos estratégicos de nuestro entorno, incluidos la ESN española de 2011 y de 2013. En este sentido el crimen organizado aparece en la mayoría de los documentos analizados como una de las principales amenazas.

En lo que respecta a Francia, el fenómeno del crimen organizado es una prioridad para la seguridad de la República francesa puesto que las actividades delictivas conducen a graves alteraciones del orden público, poniendo en riesgo incluso el buen funcionamiento de las instituciones. En este sentido, el Livre Blanc Défense et Sécurité Nationale ${ }^{64}$ identifica esta amenaza tanto para la seguridad como para la economía del país, al tiempo que alerta sobre las imbricaciones que pueden llegar a tener con los grupos terroristas.

El valor de este documento de seguridad radica no solo en la identificación del problema como una amenaza nacional, sino en el posicionamiento respecto a terceros países, que de hecho suponen un riesgo para Europa en su conjunto: "La possibilité que des territoires échappent durablement au contrôle d'un État est un risque stratégique de première

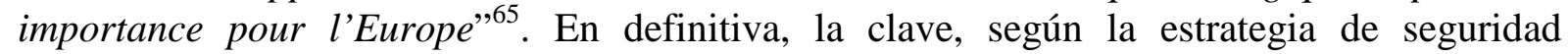
francesa, es la disuasión en común de esta amenaza, fortaleciendo los mecanismos y las capacidades comunes, al tiempo que se debe realizar un esfuerzo extra en los denominados países de origen o foco. Al mismo tiempo, no olvidan la importancia de una diplomacia comprometida e integral, al servicio de las amenazas a la seguridad. Cabe destacar que Francia plantea, de una manera amplia la lucha contra esta amenaza. A este respecto pone en valor la capacidad de intervenir por tierra y mar, más allá de las capacidades operativas tradicionales. Asimismo Francia pone en valor las oportunidades que puede ofrecer la revisión del Programa de Estocolmo 2014 ${ }^{66}$, para la seguridad europea, de cara a promover un verdadero proyecto de seguridad europea. A este respecto Francia propone mayor coherencia entre las diferentes políticas sectoriales que afectan a la seguridad, a través de los mecanismos ya creados durante estos años por la Unión Europea. Al mismo tiempo alerta contra los peligros de la mundialización en lo que al crimen organizado trasnacional se refiere, haciendo especial hincapié en la defensa de las fronteras: "Que des États se révèlent incapables d'exercer leurs responsabilités régaliennes, et ce sont les bases mêmes de l'ordre international sur lequel nous fondons notre propre sécurité qui sont menacées".

El caso de Italia es paradigmático, puesto que llama poderosamente la atención que el documento de cabecera de la seguridad ${ }^{67}$ en Italia no nombre ni una sola vez el crimen organizado. En este sentido, siendo Italia un caso paradigmático ${ }^{68}$ en lo que a la delincuencia organizada se refiere, se observa una falta incomprensible en su estrategia de seguridad.

\footnotetext{
64 "Livre Blanc Défense et Sécurité Nationale" (2013).

${ }^{6}$ Ibid., p. 55.

${ }^{66}$ Programa de Estocolmo 'Una Europa abierta y segura que sirva y proteja al ciudadano' 2010/C 115/01.

${ }^{67}$ Direttiva Ministeriale in merito alla politica militare per l'anno 2013.

${ }^{68}$ En algunas regiones Según el Fiscal General de Colombia, Luis Camilo Osorio, data del siglo XIV. Es el caso de la Camorra en la Campania italiana, con presencia exponencial en la ciudad de Nápoles. Otro conglomerado
} 
El documento estratégico ${ }^{69}$ de Reino Unido es consciente, al igual que Francia, de la amenaza que supone el crimen organizado por lo que lo ha incluido en el nivel dos, de prioridad elevada, para el Reino Unido. Actualmente, el país cuenta con más de 38.000 personas vinculadas e involucradas en el crimen organizado, con un coste para la economía y la sociedad entre 20.000 y 40.000 millones de libras.

Finlandia sitúa la delincuencia organizada como uno de los problemas fundamentales para su seguridad. En este sentido diferencia entre las amenazas militares tradicionales y los nuevos retos a la seguridad. Como factor fundamental valoran la cooperación internacional entorno a la seguridad, y, de forma especial, en la lucha contra el crimen organizado. En este sentido, el aspecto transfronterizo de las amenazas es lo que determina sus mecanismos de lucha. A este respecto, da una importancia capital a la cooperación en vecindad, esto es en la zona del Mar Báltico y en el norte, a través de una serie de objetivos mutuos en materia de lucha contra la delincuencia trasnacional. Particularmente, destaca la política trilateral existente entre Finlandia, Estonia y Rusia, en materia de lucha contra el narcotráfico. Del mismo modo, el país cuenta con un mecanismo de Cooperación Policial y Aduanera nórdica $(\mathrm{PTN})^{70}$, de cooperación y prevención de delitos de tráfico de drogas.

En el caso de Noruega, el documento estratégico, no presenta una estrategia de seguridad en sí misma, sino que se trata de una compilación de propósitos y líneas de actuación. Cabe destacar que específicamente no se señala el crimen organizado como una amenaza para la seguridad del país. Podría interpretarse la mención "to protect the society against assault and attack from state and non-state actors" a una alusión indirecta a los grupos criminales.

El documento estratégico estadounidense pone de manifiesto la debilidad de la lucha tradicional contra las nuevas amenazas. Así, confronta el fortalecimiento de las asociaciones del crimen, con la necesidad de luchar conjuntamente: gobierno, sector privado y ciudadanos individuales. En este sentido, la estrategia plantea incluir todos los niveles de gobierno y el sector privado para hacer frente a esta amenaza, como ya se viene haciendo en otros campos, como por ejemplo ante la respuesta ante los desastres naturales. La estrategia pone en valor el orden internacional actual, al tiempo que indica que esta transnacionalidad también supone en sí misma amenaza. Así, identifica amenazas transnacionales como el crimen organizado y el terrorismo, o el tráfico ilícito que continua creciendo dramáticamente en tamaño, alcance e impacto. Cabe destacar que estas amenazas no solo cruzan las fronteras y los continentes, socavando así la estabilidad de las naciones, sino que están subvirtiendo las instituciones de gobierno a través de la corrupción de los propios ciudadanos, formando alianzas con funcionarios del gobierno y algunos servicios de seguridad pertenecientes al Estado. El daño del crimen organizado es global: se han generado organismos que de forma delictiva han acumulado riqueza y poder sin precedentes a través del tráfico y otras actividades ilícitas, penetrando los sistemas financieros legítimos y desestabilizando los mercados comerciales.

mafioso con mayor proyección internacional (debido a la inmigración italiana a finales del siglo XIX a Norteamérica) es la denominada Cosa Nostra, cuyos orígenes se remontan a las sociedades feudales sicilianas. La 'Ndrangheta circunscrita en un inicio a la región de Calabria, en las localidades de Platí, Locro, San Luca, Africo y Altomonte; ha extendido su influencia y su poder hoy a 20 países (europeos, y sobre todo, a Canadá y Australia). Actualmente abarcan todo el espectro criminal, desde las redes de traficantes de droga a la explotación de la prostitución.

69 "Strong Britain in an Age of Uncertainty: The National Security Strategy", Presented to Parliament by the Prime Minister by Command of Her Majesty (Octubre de 2010).

${ }^{70}$ Las Autoridades PTN está conformada por una red de funcionarios de enlace en aproximadamente 20 países. Los funcionarios de enlace de la red sirven a todos los países nórdicos. 
La estrategia plantea una lucha contra el crimen desde una perspectiva multidimensional, que, por un lado, salvaguarde a los ciudadanos, rompa la fortaleza financiera de las redes criminales, interrumpa las redes de tráfico ilícito, combata la corrupción en el Gobierno, fortalezca el estado de derecho, refuerce los sistemas judiciales y mejore la transparencia. Así, plantea una estrategia colectiva con otras naciones que enfrentan las mismas amenazas.

De los documentos de seguridad nacional, el de Australia es el más completo en cuanto a la contención del crimen organizado se refiere. Por un lado, realiza un diagnóstico certero y extenso para prevenir, detectar e interrumpir la delincuencia organizada. De cara a afrontar el problema, considera de vital importancia la implicación de los actores legítimos no estatales como las empresas privadas, principales perjudicadas de la competición desleal que suponen muchas de las actividades delictivas: lavado de dinero, falsificaciones, ciberestafas, etc. Por parte de Australia, se considera imprescindible renovar el compromiso y apoyar a la seguridad regional y la prosperidad en el denominado siglo de Asia. Para ello, propone por un lado, mejorar las relaciones bilaterales poniendo en valor foros como la Cumbre de Asia Oriental ${ }^{71}$. En este sentido, y partiendo de la experiencia de la última década, Australia reconoce haber ampliado y adaptado sus mecanismos de lucha (inteligencia, aplicación de la ley) para combatir la delincuencia trasnacional. Así, han desarrollado un enfoque integrado para la estabilidad regional así como han puesto énfasis en la cooperación civil militar (Irak y Afganistán). Australia considera que, ante la sofisticación del crimen organizado, los sistemas, métodos y herramientas de lucha, requieren por tanto ser innovadores y eficaces: inteligencia proactiva; sólidas alianzas con los estados y territorios; concienciación de los negocios, la comunidad australiana y nuestras contrapartes internacionales; conexión con la diplomacia, la defensa, el desarrollo económico; la protección de las fronteras y la especialización de la policía. Cabe destacar que se han elaborado un amplio conjunto de Libros Blancos ${ }^{72}$, de planificación estratégica sobre las principales amenazas. En el caso que nos ocupa, sobre la Delincuencia Organizada, en el año 2010, reforzada con la Ley de Seguridad Nacional de Legislación Enmienda 2010. El país, consciente y rodeado de estados menos desarrollados, hace hincapié en las vulnerabilidades que presentan los estados fallidos o menos desarrollados ante la delincuencia transnacional, incrementado por la violencia comunal, la proliferación de armas pequeñas y armas ligeras en esos territorios, suponen una amenaza directa para la seguridad australiana, en tanto en cuanto las fronteras han desaparecido. Del mismo modo, el documento refleja la preocupación sobre el daño a la prosperidad económica y la estabilidad regional que el crimen organizado puede ocasionar en lo que al espionaje empresarial, el robo de identidad, y la negación y la interrupción de los servicios se refiere. Asimismo la capacidad de erosionar la confianza en las instituciones y los organismos encargados de hacer cumplir la ley es otro punto a tener en cuenta. Se calcula que el coste anual de la delincuencia organizada en Australia asciende a 42 billones de $\$$.

Uno de los mecanismos puesto en marcha en materia de lucha contra la delincuencia organizada ha sido la información y evaluación de todos los pasajeros y carga que entra al país. Así, las agencias transfronterizas están habilitadas para identificar y evaluar los riesgos, así como llevar a cabo las intervenciones oportunas. En términos estadísticos, esto ha

\footnotetext{
71 Destinado a promover la cooperación en asuntos políticos y de seguridad, el desarrollo, la estabilidad financiera, la seguridad energética, la integración económica y el crecimiento, para erradicar la pobreza y reducir la brecha de desarrollo en el Este de Asia, y para promover una mayor comprensión cultural. Miembros (18): Australia, Brunei, Birmania, Camboya, China, India, Indonesia, Japón, Corea del Sur, Laos, Malasia, Nueva Zelanda, Filipinas, Rusia, Singapur, Tailandia, EE.UU. y Vietnam.

${ }^{72}$ Seguridad Cibernética (2009), de Defensa (2009), de Aviación (2009), de Terrorismo (2010), de resiliencia ante los desastres (2011), Ayudas (2011), Inteligencia (2011) y sobre el papel de Australia en el siglo de Asia (2012).
} 
resultado un aumento en la incautación de artículos ilegales, incluyendo drogas y armas de fuego (procesamiento de más de 31 millones de pasajeros aéreos y marítimos internacionales, inspección de más de 100.000 contenedores de carga marítima). En lo que respecta al contrabando de personas y la migración irregular vía marítima, se han vigilado más de 140 millones de millas náuticas cuadradas de aguas de Australia y las costas. En lo que a las iniciativas transfronterizas puestas en marcha por el país destacan: Commonwealth Organised Crime Strategic Framework; Next Generation Border Security; Bali Process on People Smuggling, Trafficking in Persons and Related Transnational Crime. Asimismo han implementado las siguientes iniciativas a nivel nacional: National Criminal Intelligence Fusion Capability; Commonwealth Organised Crime Strategic Framework; el National Organised Crime Response Plan; el Criminal Asset Confiscation Taskforce. Del mismo modo, trabajan conjunamente con la industria y la tecnología, para hacer del país un blanco difícil para la delincuencia organizada. Llevan a cabo un dilatado intercambio de inteligencia y cooperación en los procedimientos penales formales con los socios internacionales en la aplicación de la ley. Ayudan a los países socios en el fortalecimiento de las instituciones jurídicas, administrativas y de seguridad por el apoyo a su aplicación de la Convención contra la Corrupción y la Anti-Bribery Convention de la OCDE. Apoyo a la labor analítica y estadística de la ONU y otras organizaciones para comprender mejor la corrupción y las tendencias delictivas transnacionales en Asia oriental y el Pacífico. En definitiva, Australia hace frente a esta amenaza con numerosos mecanismos que trabajan en red y de forma combinada, colaborando a nivel internacional con los principales mecanismos legales creados a tal efecto. Cabe destacar el enfoque real a la prevención realizado por el Gobierno australiano, así como a la puesta en valor de sus capacidades y su particular situación territorial estratégica. Una de las claves es el trabajo con el resto de países, intentando fortalecer las instituciones y las sociedades en los países exportadores de crimen organizado de la región. De cara al futuro, plantea los siguientes retos en materia de crimen organizado: mejorar el intercambio de información, donde se efectúen los marcos legislativos necesarios, a través de agencias estatales, y con los estados y territorios, socios internacionales y empresas australianas; continuar implementando estrategias esbozadas en el Marco Estratégico de la Commonwealth la delincuencia organizada y el Plan Nacional de Crimen Organizado de respuesta , con un enfoque en las respuestas Entrega inter-jurisdiccionales; alentar los esfuerzos en curso regional para combatir la corrupción, el tráfico de personas y la delincuencia organizada transnacional sobre la base de una mejor comprensión de los fenómenos; contar con los gobiernos, el sector privado y la comunidad para que Australia un blanco difícil para la delincuencia grave y organizada; mejorar nuestro enfoque integral de la seguridad en las fronteras; seguir invirtiendo en nuevas tecnologías; desarrollar una Estrategia de Seguridad Nacional cada cinco años;

Japón es consciente de que la delincuencia organizada transnacional y el terrorismo están estrechamente vinculados, y que suponen una amenaza que debe prevenir y combatir con la cooperación y el apoyo internacional. Así, en su documento estratégico, relaciona el avance de la globalización y la innovación tecnológica como un impacto negativo para los sindicatos del crimen, configurando una amenaza grave para la seguridad de cualquier país. El país nipón identifica una serie de variables que han propiciado las actividades delictivas a nivel internacional: el cambio en el equilibrio de poder, los rápidos avances de la innovación tecnológica o la amenaza de la proliferación de armas de destrucción masiva, el terrorismo internacional, los conflictos entre Estados por recursos naturales. Japón considera un riesgo extra los incidentes en el mar (litigio de soberanía entre los Estados ribereños y China; preocupaciones sobre el servicio del imperio de la ley en el mar; la libertad de navegación o la estabilidad en la zona del sudeste asiático), han supuesto un incremento de altercados y 
pequeñas crisis y situaciones inesperadas para las que hay que estar preparados. No obstante la identificación de estos riesgos, la estrategia ni propone ni analiza ningún mecanismo de lucha.

\section{Conclusiones}

La delincuencia trasnacional se ha convertido en una de las principales amenazas y retos para la seguridad nacional. Su incremento exponencial en los últimos años, y su extensión sin paliativos, pone de manifiesto que esta amenaza ha venido para perpetuarse en nuestras sociedades.

Lo más destacado a lo largo del análisis ha sido interpretar que al tratarse de una amenaza global, debe ser combatida en los mismos términos, por lo que los mecanismos encaminados a luchar contra esta amenaza deben ser transversales y comprehensivos, y deben extenderse no solo a nivel nacional, sino también regional e internacional.

En lo que respecta a los medios para su contención, a pesar de los mecanismos existentes, se puede considerar un éxito per se, la sola inclusión de este fenómeno en las principales Estrategias de Seguridad Nacional de los países de nuestro entorno. A este respecto, y en aras a un ulterior desarrollo y mejora de estos mecanismos, es necesario fijar una serie de objetivos comunes por parte de los Estados, puesto que la clave del éxito de la lucha contra esta amenaza radica fundamentalmente en la lucha común y en las acciones conjuntas que los propios Estados lleven a cabo.

Tal y como demuestran las ESN de Estados Unidos o de Australia, los mecanismos e instrumentos nacionales, regionales, o entre países limítrofes son necesarios y beneficiosos, puesto que solucionan el problema de forma particular o local, siendo más efectivos en términos cuantitativos. Muchas de las amenazas son de carácter regional, por lo que la cooperación trasfronteriza debe ser tenida en cuenta como una herramienta fundamental. En este sentido, en clave comparada, nuestro país se encuentra en línea con los países de su entorno, si bien la estrategia puede ser un simple documento si no se implementan acciones y proyectos que se prevén en materia de lucha contra el crimen.

En clave nacional, la propia puesta en marcha de una Estrategia de Seguridad Nacional, es un primer paso muy importante. Adicionalmente es necesario valorizar los esfuerzos realizados por los Gobiernos a la hora de crear y coordinar una estrategia de seguridad a nivel estatal, que supere los intereses y visiones parciales propias de los ministerios del ramo, y que englobe de forma clara un enfoque verdaderamente multidisciplinar. Adicionalmente es necesario el compromiso nacional al máximo nivel de lucha contra la corrupción en el seno de las organizaciones, para que no se dinamite desde dentro el Estado de derecho.

La Estrategia de Seguridad Nacional puede ser por tanto un potente y útil elemento de lucha contra las amenazas a nuestra seguridad, o puede ser simplemente un documento más, una mera declaración de intenciones. La diferencia radicará ya no tanto en el contenido de la misma, sino en la capacidad de las instituciones, los nuevos actores y los grupos creados ad hoc para llevarlos a cabo y proyectarlos de forma efectiva. En las últimas décadas se han puesto en marcha diversas medidas para luchar contra el crimen organizado, no obstante las acciones futuras deberían estar encaminadas a la promoción de medidas claras de represión, 
orientadas a disminuir las oportunidades criminales, y la adopción de una respuesta proporcional a la amenaza ${ }^{73}$.

Es necesario subrayar la dificultad añadida en lo que a la cooperación entre países se refiere en el caso de países no equiparables en estándares democráticos, entramados legales o fuerzas y cuerpos de seguridad. Los países en vías de desarrollo se convierten en no pocos casos en auténticos obstáculos en la cooperación con los principales países desarrollados, debido a la corrupción política y policial endémica existente ${ }^{74}$.

\footnotetext{
${ }^{73}$ Giménez-Salinas, op. cit.

${ }^{74}$ Naím, M. (2006): Ilícito: cómo traficantes, contrabandistas y piratas están cambiando el mundo, Madrid, Debate.
} 